\title{
Building a Postwork Utopia: Technological Unemployment, Life Extension and the Future of Human Flourishing
}

In LaGrandeur and Hughes (eds) Surviving the Machine Age (Palgrave-MacMillan 2017)

By John Danaher*

\begin{abstract}
Populations in developed societies are rapidly aging: fertility rates are at all-time lows while life expectancy creeps ever higher. This is triggering a social crisis in which shrinking youth populations are required to pay for the care and retirements of an aging majority. Some people argue that by investing in the right kinds of lifespan extension technology - the kind that extends the healthy and productive phases of life - we can avoid this crisis (thereby securing a 'longevity dividend'). This chapter argues that this longevity dividend is unlikely to be paid if lifespan extension coincides with rampant technological unemployment. This does not mean that we should not pursue lifespan extension, but it does mean that the argument in its favor needs to rest on other grounds. After articulating these grounds, the chapter proceeds to consider the implications this has for our vision of the extended life, postwork utopia. It argues that this vision may need to be reconceived and suggests that one plausible reconception involves prioritizing the role of games in the well-lived life.
\end{abstract}

\section{Introduction - Unemployment in an Aging World}

Susannah Mushatt Jones died the day I wrote this sentence. She was the oldest person in the world at the time, aged 116 years at her death. Her life spanned three centuries: the nineteenth, twentieth and twenty-first. As an African-American woman she witnessed profound social, economic and legal changes in her lifetime, including the election of the first black president. She lived the last 30 years of her life in a public housing facility for senior citizens in Brooklyn New York (BBC News 2016). She was blind and partially deaf. She was under constant care towards the end - though she maintained an active role as a member of her nursing home's tenant patrol until she was 106.

If current medical and demographic changes continue, we can expect to see more people like Susannah Mushatt Jones in the future. This has important social repercussions. Life expectancy has increased dramatically in the $20^{\text {th }}$ and 21st centuries (National Institute on Aging 2011). At the same time, fertility rates have gone down across the developed world (Worldbank 2016). Countries like Japan, where life expectancy now stretches to the mid-80s, and birth rates are at record lows, are facing significant social and economic problems as a result of their 'super-aging' populations (Muramatsu and Akiyama 2011). If the

\footnotetext{
* Lecturer in Law, NUI Galway - john.danaher@nuigalway.ie
} 
elderly spend the last decades of their lives requiring near-constant nursing and medical care and if there is a rapidly shrinking younger population coming up behind them, who will pay for it all? How will societies cope with this demographic shift?

Call this the super-aging society problem (SAS problem for short). The SAS problem is bad in and of itself, but it becomes even more pronounced when considered in conjunction with the possibility of widespread technological unemployment. If the predictions of authors like Ford (2015), Brynjolfsson and McAfee (2014), Frey and Osbourne (2013) and others prove to be correct, then not only will shrinking youth populations in countries like Japan be required to pay for the care of the super-aging majority, they will have to do so while confronting fewer and fewer employment opportunities and greater social inequality. Now, perhaps the robots themselves can help with the care - as is already happening - but is this something to be welcomed or lamented? Are there other important values at stake when we think about the intersection between aging and technological unemployment?

These are the questions that this chapter sets out to answer. In the course of doing so it presents three main arguments. First, it looks to Olshansky et al's (2007) case for the longevity dividend - the claim that societal benefits result from the expansion of healthy lifespan - and argues that although this argument provides a solution to the SAS problem when considered in isolation from technological unemployment, it becomes less compelling when considered in conjunction with it. Second, despite this there is still a good independent case for lifespan extension. Third, because of this we need to radically rethink what the ideal future for human society will look. We need to plan for a future in which people live longer healthier lives but no longer work or contribute to the economic productivity of their societies.

\section{Assumptions and Clarifications}

Before I get into the substance of my claims, I need to clarify some key terminology and value assumptions that motivate the arguments I am going to make. I will start with the most important - and interestingly most controversial - assumption, namely:

Value of Life Extension: All else being equal, it is better to live a longer life. This implies that, all else being equal and if possible, we should try to extend people's lifespans.

Some philosophers will shake their heads at this claim, so it is important for it to be interpreted properly. First, the 'all else being equal' clause is crucial. There are certain factors which, if they hold true, could negate the assumption that continued life has value. A person could be living in interminable pain (mental or physical) that makes continued life unbearable. For this person simply extending their lifespan might not make things better. Similarly, the obligation that allegedly follows from the value assumption - viz. that we should extend life - is 
not absolute. It can be overridden by other considerations or obligations. For instance, if a person does not wish to live any longer it would be wrong to impose additional life years on them against their will. We should respect their informed decision: autonomy trumps forced existence. Likewise, there are other social and moral obligations that could intervene and make it wrong to extend life. Resources are scarce and there may be occasions on which extending life comes at the expense of something even more important. Still, there are important questions to be asked as to what could be more important than lifespan extension, particularly given that continued life is usually what makes all other good things possible. We will return to this issue below.

This brings us to a second interpretive point. The value assumption claims that more life is 'better' but it is deliberately ambiguous as to what this betterness consists in and to whom it accrues. The obvious interpretation would be that more life is better in the sense that it results in more valuable experiences and states of being for the person who is living that life. But it is possible that other, more extrinsic values, result from lifespan extension. These values could accrue to the person's friends and family (e.g. continued friendship), as well as to the broader society in which they live. At the same time, there could be instrumental costs to others and to the broader society that are ignored if you focus purely on the benefits to the individual. So we should be sensitive to the effects of longevity outside of the individual. This is something implicit in my formulation of the SAS problem in the introduction, and will resurface when we discuss the longevity divided argument, below.

Finally, this way of characterizing the value of lifespan extension includes hedges against some noteworthy philosophical objections. For example, there are a number of philosophers who claim that the value of continued existence eventually levels off and/or reverses itself. Williams (1973) is probably the most famous purveyor of this argument. He claimed that anyone living an immortal life would reach a point in time when they became incredibly bored and no longer lived a valuable life. Others have defended similar claims about the questionable value of indefinite lifespan extension (Smuts 2011; Scheffler 2013). These claims typically centre around the notion that certain essential goods (e.g. a sense of achievement or purpose) dissipate if life goes on indefinitely, or around the notion that the goods of human life require a certain degree finitude to make sense. Nothing I say here necessarily disputes these claims. It could well be that immortality is bad and that the goods of life require finitude. I simply assume that we haven't yet extended lifespans to the point where we are at risk of undermining these goods. Thus, for the time being, and all else being equal, adding to lifespan is better than not adding to it.

This value assumption lurks in the background for the remainder of this chapter, occasionally resurfacing for defence and refinement. I will also be making use of some additional terminology that is in need of clarification. First of all I will be using the term 'lifespan extension' in two distinct senses:

Lifespan Extension-1 (LE1): You extend the relatively high cost, unhealthy and 'aged' portion of human life. 
Lifespan Extension-2 (LE2): You extend the relatively lower cost, healthy and 'youthful' portion of human life.

The first sense of the term captures a current reality. We are already getting quite good at extending the relatively high cost, unhealthy and 'aged' (I put this in scare quotes because terms like 'aged' are possibly best understood relative to some norm of lifespan; hence as lifespan extends, what counts as aged may shift in line with the new norm). Individuals like Susannah Mushatt Jones exemplify this mode of lifespan extension. They live extended periods of time in states of relatively low health, heavily dependent upon the care of others. This form of life extension has been facilitated by advances in fighting diseases (infectious, heart, cancer and so on) and in palliative care.

The second sense of the term captures a possible reality, one that numerous futurists and transhumanist activists would like to realize (Kurzweil and Grossman 2004 \& 2010; de Grey and Rae 2008). This form of life extension takes issue with current approaches to medical care which don't take seriously the value of reversing or reducing the negative health effects of aging. It wishes to expand the parts of life where people are healthy and relatively less dependent on the care of others for their continued existence. LE2 is thus something that these futurists and activists think we should aim for, usually following the basic value assumption that the more healthy life the better.

It is the intersection between lifespan extension (of both varieties) and trends in employment and automation that are the central concern of this chapter. It is consequently worth clarifying some terms associated with those latter topics too. Three are particularly important

Technological Unemployment (TU): A state of affairs in which robots/machines/advanced AI (etc) replace most forms of human paid labor.

Polarization Effect (PE): The division of human forms of labor into two polarized extremes: high-paid abstract labor on the one had and low-paid manual labor on the other (Autor 2015).

Basic Income Guarantee (BIG): The provision of a guaranteed income to all persons within a politically circumscribed society, irrespective of their ability or willingness to work.

TU and BIG are relatively self-explanatory. PE might a little more unfamiliar. It is an effect described by the economist David Autor (2015). It is relevant here because some people dismiss the more extreme arguments in favor of rapidly increasing TU. Economists are often of this view because they think proponents of TU commit the 'lump of labor' fallacy, i.e. they assume that there is a fixed amount of labor out there and that if machines get good at the existing forms of labor, humans will have nowhere left to go. This assumption is flawed because there are always new jobs coming on stream that take into account the things 
made possible by technology (e.g. social media consultant or machine learning consultant). Thus, technology doesn't lead to widespread unemployment; it simply changes the employment opportunities available to human laborers. Autor's PE is interesting because it effectively accepts this critique of TU. It simply points out that the main discernible effect of technology on employment (at the moment) is a polarizing one: advances in IT are creating relatively few highly-paid and highly-educated 'abstract' jobs; they are destroying middleincome, middle-skill jobs; and they are resulting in many more low-paid, poorlyeducated and precarious 'manual' jobs. Thus, even if we don't get to a state of TU, we are entering a world of increased labor force stratification.

The existence of PE has one important implication for the remainder of the chapter. It means that we can probably hedge our bets between PE and TU and many of the arguments I make will still hold true. This is because most of arguments are premised upon increased polarization, precarity and inequality, not widespread TU itself. I will occasionally highlight this when presenting those arguments.

Speaking of which, it is about time I got to the arguments themselves.

\section{Will there be a Longevity Dividend?}

Return to the super-aging society (SAS) problem that I outlined in the introduction. We are now able to get a clearer sense of the causes of this problem. In essence, the SAS problem results from a combination of LE1 and low fertility rates. It is the fact that we are getting better at extending the relatively unhealthy and dependent phase of live, coupled with the fact that there are fewer young people to pay for the care of the aging population, that causes the problem. This combination often scares policy-makers and politicians. It suggests to them that it's a bad thing to further prioritize lifespan extension. It suggests that the SAS problem is one of the considerations that might count against or override the value presumption in favor of lifespan extension. A possible solution would be to increase fertility by some compensating measure. But this too is a concern for policy-makers because lower fertility correlates fairly consistently with higher living standards, and there are additional concerns about the resource drain created by larger global populations.

This is where proponents of LE2 step in. They argue that policy-makers have been focused on the wrong type of lifespan extension. It is true that LE1 contributes the SAS problem, but LE1 is not the only game in town. There is also LE2. If we prioritized investments into LE2 over investments into LE1 we could address the SAS problem without going down the route of increasing fertility. This is the so-called 'longevity dividend' argument. Olshansky et al $(2007,12)$ put it as follows:

"[A]ging interventions have the potential to do what no surgical procedure, behavior modification, or cure for any one major fatal disease can do; namely, 
extend youthful vigor throughout the life span. Extending the duration of physical and mental capacity would permit people to remain in the labor force longer, amass more income and savings, and thereby lessen the effect of shifting demographics on age- based entitlement programs, with a net benefit to national economies. The combined social, economic, and health bonuses accruing from a slowing of the rate of aging is what we call the longevity dividend - benefits that might begin with those now alive, and then continue for all generations that follow."

Goldman et al (2013) model possible future scenarios in which we invest in LE2 over and above LE1. They reach a number of interesting conclusions. They claim that prioritizing therapies that delay aging even by as much as 2.2 years could yield economic benefits of $\$ 7.1$ trillion over a period of fifty years. By contrast, focusing on the disease prevention strategies at the heart of LE1 (e.g. prevention of heart disease and cancer) would yield diminishing improvements over the same period. They acknowledge that delayed aging could have severe economic disbenefits if existing old age entitlements remain in place, but claim that those disbenefits can be offset if we increase entitlement ages in tandem with the delayed aging effect.

We see thus, in both cases, the claim that LE2 avoids the SAS problem by adding additional healthy and economically productive years to life. When read in its common prosaic form, this argument often seems pretty persuasive and common-sensical. But it is often only when you expose the logical structure of an argument that you begin to see certain problems. For example, here's one plausible reconstruction of the reasoning underlying the longevity dividend argument:

(1) It is possible to avoid the SAS problem by extending the healthy and economically productive years of life.

(2) LE2 extends the healthy and economically productive years of life.

(3) It is possible to achieve LE2 by prioritizing medical research and investment into anti-aging therapies.

(4) Therefore, it is possible to avoid the SAS problem by prioritizing medical research and investment into anti-aging therapies.

The reasoning has a certain appeal. The second premise seems true by definition. The third premise is empirically uncertain but we can grant for the sake of argument that it is true: that we really can achieve LE2 by prioritizing the right research. That leaves us with first premise. This seems persuasive if we presume a relatively static and unchanging economic model, i.e. one in which human workers contribute the bulk of the economically productive labor, that this work will be well-rewarded, and that the workers will pay their fair share of tax (or charity) towards the remaining entitlement programs.

But of course this presumption is exactly what is challenged by TU and PE. If the economic model shifts dramatically over the next fifty years - to such an extent that there are few if any jobs for human workers (and the jobs that are available are precarious and poorly rewarded) - then the longevity dividend will 
never be paid. In other words, contrary to what its proponents believe the combination of LE2 and TU (or PE) will not resolve the SAS problem. In fact, the combination may exacerbate the problem. It would result in more people living longer and healthier lives, while being unable to make an economic contribution, and consequently reliant on the state (or charities) to sustain their existence. We don't just get an old-age dependency problem; we get a whole-life dependency problem. Policy-makers may get worried again. They may insist that LE2 cannot now be prioritized because it will drain resources over two timelines: in the initial investment phase and in the long-term (if the research succeeds in achieving LE2).

The result is that the longevity dividend argument becomes a good deal less persuasive in a world of rampant TU. Does this, in turn, undercut the argument for lifespan extension? It may weaken it to a degree, but this is arguably only because the longevity dividend argument rests an inappropriate amount of weight on the extrinsic, societal benefits of longevity. This is probably not where the weight should be. There is a simple and strong independent case for LE2. Many people feel its pull. The common sense view is that death is pretty bad (all else being equal), and that old age and suffering are bad too. This is supported by most leading philosophical accounts of well-being and death. Most philosophers think that death is a bad thing because it deprives you of good things you might otherwise have had (Luper 2009). Even philosophical schools of thought that argue in favor of the view that death is not bad (or not to be feared) tend to also support the view that death is 'less good' than continued life (Warren 2004; Smuts 2012). Furthermore, standard experiential or objective list views of well-being tend to insist that a good life is one in which our physical and mental capacities are allowed to reach their maximum potential (e.g. Sen and Nussbaum 1993). This is something that is not possible in a state of aging illhealth and dependency. Combining these two views, we get a case in favor of LE2 that rests no weight on the extrinsic economic benefits. Indeed, one could argue that this argument is truer to the real rationale and motivations behind the drive for LE2; that the longevity dividend argument is something a convenient smokescreen, revealed to be such by the impending possibility of TU.

\section{Flourishing and Well-Being in a Postwork Age}

Suppose this independent argument is correct, does this mean we should pursue LE2 with abandon? Supporters must contend with two objections. The first returns to the territory of the SAS problem. The policy-maker may concede that there are strong independent grounds (viz. the badness of death and the goodness of healthy life) for supporting investment into LE2 but still insist that we must confront the economic reality: it will result in more people being dependent on others for their existence (if they want it to be happy and flourishing). We can no longer commit to the view that LE2 will solve this problem by itself - as the proponents of the longevity dividend liked to do - so we must say something in response. 
And there are several things we can say. First, this may not be a problem at least not in the sense we understand it to be. Our assumption that we will need to pay a lot for the upkeep or support of dependent populations may itself be disrupted by the coming technological changes. As Brynjolfsson and McAfee (2014) put it, the future may be one of increasing abundance and increasing spread. That is to say, there may be greater inequality in terms of income and wealth, but the poorer populations will be living in states of machine-assisted abundance. They will have all the goods and services they could possibly require. Indeed, as I suggested earlier, this could include machine-assisted abundance in the area of care and assistance for the remaining elderly or ill populations that require it. Furthermore, there are plausible ways in which we can address the problem of increasing spread. The BIG is one such way - now recommended or encouraged by many of the leading contributors to the debate about TU. Other chapters in this book (e.g. Santens) explore this policy option in greater detail so I will say relatively little about it here. All I will say is that pointing to the combination of TU and lifespan extension (either LE1 or LE2) may be a boon for proponents of BIG. Why? Because it intensifies the pragmatic concerns $\mathrm{s}^{\mathrm{ii}}$ that motivates many of the arguments in favor of BIG. It would thus make sense for such proponents to add the economic effects lifespan extension to their arsenal of push factors that nudge us toward the BIG.

The second objection is rather more interesting. It argues that just as the supporter of the longevity dividend saw one of their key premises undercut by the impending reality of TU, so too will the independent supporter of LE2 see one of their key premises undercut. How does this work? I take the following to be a reasonable reconstruction of the independent argument for LE2:

(5) It is good for people to live longer lives in states of flourishing and wellbeing.

(6) LE2 allows people to live longer lives in states of flourishing and wellbeing.

(7) Therefore, LE2 is good.

The problem here is that premise (5) may be less plausible in a world of rampant TU (or indeed PE). This is because whatever about the income it may provide, paid employment is, for many people, a privileged context in which they can achieve goods that make flourishing and well-being possible. Ghaeus and Herzog (2016) express the objection nicely when they argue that there are four nonmonetary goods that are associated with work: (i) mastery/excellence; (ii) community; (iii) social contribution and (iv) status. The first of these is particularly important because work is often what allows us to exercise certain cognitive and physical capacities to their maximum potential, which is something intrinsic to many theories of flourishing. The problem, as Ghaeus and Herzog point out, is that BIG may not be able to compensate for the loss of these goods. So people living longer and healthier lives in a world without work may not be so conducive to flourishing and well-being. 
In previous work (Danaher 2016), I have argued that this pessimistic view must be counterbalanced against the fact that work is, for many people, a source of misery and frustration, and, furthermore, that there are many nonmonetary contexts which allow for excellence, social contribution, community and status to develop. Indeed, the advantage of TU may be that it allows these other contexts to assert themselves more forcefully. Still, even I have my doubts about living a long and flourishing life in a world without work. In the remainder of the chapter I want to consider these doubts and explore a radical possibility that allows us to embrace the combination TU and LE2, without lamenting the economic, social or personal repercussions.

\section{The Postwork Utopia as a World of Games}

My doubts about flourishing in a postwork future rest on the possible 'meaning deficit' that could arise in such a world. Meaning is a distinct component of well-being. It is a contested philosophical concept, but for present purposes I will focus one plausible theory, taken from the work of Thaddeus Metz (2010). This theory argues that our lives accumulate meaning when we contour our intellects to the pursuit of the good, the true and the beautiful. In other words, when we act to bring about morally good states of affairs, pursue and attain a true conception of reality, and produce (and admire) things of great aesthetic beauty. It is critical to this theory that your individual actions help to achieve these three great states of affairs. In other words, there must be a link (typically causal and/or mental) between what you do and what happens in the world around you. The problem is that the automating technologies that make TU an impending reality also threaten to sever that causal-mental link between what you do and what happens in the world around you. Automating technologies, after all, obviate the need for humans in certain endeavors.

The problem then with those, like me, who insist that paid work is often boring and degrading, and that we would be better off without it, is that we tend to assume that if we can achieve TU and BIG, then the automating technologies that make this possible will simply free us up to pursue things that provide opportunities for genuine meaning and flourishing. But it may not work that way. There is no good reason to think that advances in automating technologies limit themselves to activities that provide less meaning for humans. In fact we already know that technological developments affect other domains where we would like humans to remain relevant. For example, if we assume that science is the main way in which we pursue 'the true' in the modern world, then there are already some obvious ways in which automating technologies are removing us from this domain of meaning. Science is increasingly a big data enterprise, in which machine learning algorithms are leveraged to make sense of large datasets, and to make new and interesting discoveries. These systems are in their infancy now, but already we see ways in which the algorithms are attenuating the link between individual scientists and new discoveries. Why? Because they are becoming increasingly complex, and working in ways that are beyond the understanding and control of the individual scientists. The crucial causal-mental link is being cut. 
The resulting concern is that developments in automating technologies may narrow the domain for genuinely meaningful action. There are no doubt meaningful activities will remain accessible to humans (e.g. there are serious questions as to whether machines could ever really takeover the pursuit of the Beautiful), but the totality will diminish in the wake of rampant automation. Humans could still be very well off as a result: we could build a world of abundance in which machines solve most moral problems (e.g. curing disease, distributing goods and services, deciding on and implementing important social policies) make new and interesting discoveries in which we can delight, and in which we are richly rewarded by their technological acceleration, but we will be the passive recipients of these benefits, not active contributors to them. There is something less-than-idyllic about such a world.

This is where we may need to radically rethink what it takes to live a long meaningful and flourishing life.iii One thing that would be left open to us in this postwork future is game-playing. While the machines are busy solving our moral crises and making great discoveries, we can participate in more and more elaborate and interesting games. These games would be of no instrumental significance - they wouldn't solve moral problems or be sources of income or status, for example - but they might be sources of meaning and they might allow for a genuinely utopian form of flourishing.

To understand how this might happen, we need to get a better handle on what a game is. I rely on the conceptual analysis provided by Bernard Suits (2005). Suits argues that games have three key features:

Prelusory Goals: These are outcomes or changes in the world that are intelligible apart from the game itself. For example, in a game like golf the prelusory goal would be something like: putting a small, dimpled ball into a hole, marked by a flag. The prelusory goal is the state of affairs that helps us keep score and determine who wins or loses the game.

Constitutive Rules: These are the rules that determine how the prelusory goal is to be attained. According to Suits, these rules set up artificial obstacles that prevent the players from achieving the prelusory goal in the most straightforward and efficient manner. For example, the most efficient and straightforward way to get a dimpled ball in a hole would probably be to pick up the ball and drop it directly in the hole. But the constitutive rules of golf do not allow you to do this. You have to manipulate the ball through the air and along the ground using a set of clubs, in a very particular constrained environment. These artificial constraints are what make the game interesting.

Lusory Attitude: This is the psychological orientation of the game-players to the game itself. In order for a game to work, the players have to accept the constraints imposed by the constitutive rules. This is an obvious point. Golf could not survive as a game if the players refused to use their clubs to get the ball into the hole.

Here's the critical question: can a world in which we have nothing to do but play games (so-defined) provide the basis for a flourishing life? Maybe. Suits himself seems to have thought it would be the best possible life. But Suits was 
notoriously esoteric in his defence of this claim. His book on the topic, the Grasshopper, is an allegorical dialogue, which discusses games in the context of a future of technological perfection, but doesn't present a clearcut argument. It is also somewhat equivocal and uncertain in its final views, which is what you would expect from a good philosophical dialogue. This makes for good reading, but not good arguing. We need to turn to the work of other philosophers like Thomas Hurka (2006) to fill in the details missing from Suits's account. Doing so we see how Hurka argues that games are a way of realising two important kinds of value in their purest and most idealized form.

The first value derives from the structure of means-end reasoning. Means-end reasoning is all about working out the most appropriate course of action for realizing some particular goal. A well-designed game allows for some complexity in the relationship between means and ends. Thus, when one finally attains those ends, there is a great sense of achievement involved (you have overcome the obstacles established by the rules of the game). This sense of achievement, according to Hurka, is an important source of value. And games are good because they provide a pure platform for realizing higher degrees of achievement. An analogy helps to make the point. Compare theoretical reasoning with practical reasoning. In theoretical reasoning, you are trying to attain true insights about the structure of the world around you. This enables you to realise a distinct value: knowledge. But this requires something more that the mere description of facts. You need to identify general laws or principles that help to explain those facts. When you succeed in identifying those general laws or principles you will have attained a deep level of insight. This has more value than mere description. For example, when Newton identified his laws of gravity, he provided overarching principles that could explain many distinct facts. This was valuable in a way that simply describing facts about objects in motion was not: there was an extra value to providing knowledge that was explanatorilyintegrated. Hurka argues that the parallel to knowledge in the practical domain is achievement. There is some good to achievement of all kinds, but there is greater good in achievement that involves some means-end complexity. The more obstacles you have to overcome, the more achievement you have. Games are special because they allow us to create ever more elaborate and complex forums for these higher forms of achievement, ones that aren't limited in their complexity like real-world means-end problems. In other words, a well-designed game can be a forum par excellence for achieving this type of value.

The second source of value in game-playing has to do with Aristotle's distinction between two types of activity: energeia and kinesis. Energeiai are activities that are all about process. Aristotle viewed philosophy and selfexamination as being of this sort: it was a constant process of questioning and gaining insight: it never bottomed out in some goal or end state. Kineseis are activities that are all about goals or end states. Aristotle thought that processrelated activities were ultimately better than goal-related activities. The reason for this is that he thought the value of a kinesis was always trumped by or subordinate to its goal (i.e. it was always instrumental and never good in itself). This is why Aristotle advocated the life of contemplation and philosophising. Such a life would be one in which the intellectual activity is an end in itself. 
At first glance, it would seem like games don't fit neatly within this Aristotelian framework. Games are certainly goal-directed activities (the prelusory goal is essential to their structure). And so this makes them look like kineseis. But remember the goals are essentially inconsequential. They have no deeper meaning or significance. As a result, the game is really all about process. It is about finding ways to overcome the artificial obstacles established by the constitutive rules. Games are consequently excellent platform for realizing the Aristotelian ideal. They are activities directed at some external end, but the end itself has no value; the internal process is the sole source of value. Indeed, there is a sense in which games are an even better way of achieving Aristotle's ideal than Aristotle's own suggestion. The problem with Aristotle's suggestion is that intellectual activity often does have valuable goals lurking in the background (e.g. attaining some true insight). There is always the risk that these goals trump the inherent value of the intellectual process. With games, you never have that risk. The goals are valueless from the get-go. Purely procedural goods can really flourish in the world of games.

This makes a postwork world, consisting of nothing but elaborately constructed games look like a world that allows for a certain kind of flourishing. But is this flourishing enough? Ironically, Hurka has his doubts. While he accepts that the game-playing life allows for some flourishing, he still thinks it is of a weaker or inferior sort because the players are cut off from true sources of meaning like the good and the true. This suggests a retreat to the vision of meaning I outlined earlier.

But I want to suggest that Hurka. There may be nothing inferior about a world in which humans are no longer concerned with things like the good and the true. Indeed, this world of elaborate but ultimately inconsequential games is arguably the most plausible conception of what a utopian world would look like. If you think about it, the other proposed sources of meaning (e.g. the good and the true) only really make sense in an imperfect world. It is because people suffer or lack basic goods and services that we need to engage in moral projects that improve their well-being and resolve distributional injustices. Similarly, it is only because we are epistemically impaired that we need to pursue the truth. If we lived in a world in which those impairments had been overcome, the meaning derived from those activities would no longer make sense. The external goods would be readily available to all and would no longer be a source of concern or longing. In such a world, we would expect the purely procedural goods alluded to by Hurka to be the only game in town. And what is a world devoid of suffering, impairment and limitation? Surely it is a utopia? By enabling us to see the value of game-playing as a source of flourishing, this might be exactly what the combination of TU and LE2 helps us to bring about.

\section{Conclusion}

Where does this analysis leave us? A brief summary is in order. First, the SAS problem is definitely a problem: one that societies need to confront. 
Furthermore, they will not be able to confront it simply by prioritizing LE2 over LE1, as proponents of the longevity dividend argument would have us believe. This is because that argument neglects to consider the potential impact of TU on its motivating premise. But this does not mean that LE2 is unworthy of our support. It deserves our support if we grant that there is value (in most circumstances) to avoiding death and living in states of flourishing and wellbeing. Nevertheless, defenders of LE2 still need to think about how the distributional crises exacerbated by SAS and TU will be resolved and, perhaps most importantly, about what meaning and flourishing look like in a world of rampant automation. I have suggested that we may need to embrace a radical vision in which TU and LE2 make possible a utopian, game-playing mode of existence.

\section{Bibliography}

Autor, D. (2015a). Why are there still so many jobs? The history and future of workplace automation. Journal of Economic Perspectives, 29(3), 3-30.

BBC News (2016). 'Susannah Mushatt Jones, last US woman born in 19th Century, dies'. 13 ${ }^{\text {th }}$ May 2016

Brynjolfsson, E., \& McAfee, A. (2014). The second machine age: Work, progress, and prosperity in a time of brilliant technologies. WW Norton and Co.

Danaher, J. (2016). Will life be worth living in a world without work? Science and Engineering Ethics. doi:10.1007/s11948-016-9770-5

Ford, M. (2015). The rise of the robots: Technology and the threat of a jobless future. New York: Basic Books.

Frey, C. B., \& Osborne, M. A. (2013). The future of employment: How susceptible are jobs to computerisation. Oxford Martin School, Working Report.

Gheaus, A., \& Herzog, L. M. (2016). The goods of work (other than money). Journal of Social Philosophy. http://philpapers.org/rec/GHETGO . Accessed May 15th, 2016.

Goldman, D. et al (2013) Substantial health and economic effects from delayed aging may warrant a new focus for medical research. Health Affairs 32(10): 1698-1705.

de Grey, A. and Rae, M. (2008). Ending Aging. St Martin's Press.

Hurka, T. (2006). Games and the Good. Proceedings of the Aristotelian Society 106(1): $217-235$. 
Kurzweil, R and Grossman, T. (2004). Fantastic Voyage: Live Long Enough to Live Forever. Rodale Press.

Kurzweil, R. and Grossman, T. (2010). Transcend: Nine Steps to Living Well Forever. Rodale Press.

Luper, S. (2009). The Philosophy of Death. Cambridge: Cambridge University Press.

Metz, T. (2010). The good, the true and the beautiful: Toward a unified account of great meaning in life. Religious Studies 47(4): 389-409.

Muramatsu, N and Akiyama, H. (2011). Japan: Super-aging Society Preparing for the Future. The Gerontologist 51(4): 425-432.

National Institute on Aging (2011). Global Health and Aging (Report).

Washington DC: NIA, NIH, WHO. Available at https://www.nia.nih.gov/research/publication/global-health-and-aging/livinglonger

Olshansky, SJ, Perry, D, Miller, R and Butler, R. (2007). Pursuing the Longevity Dividend: Scientific Goals for an Aging World. Annals of the New York Academy of Sciences 1114(1): 11-13

Scheffler, S. (2013). Death and the Afterlife. Oxford: OUP.

Sen, A. and Nussbaum, M. (eds) (1993). The Quality of Life. Oxford: OUP

Smuts, A. (2011). Immortality and Significance. Philosophy and Literature 35(1) 134-149.

Smuts, A. (2012). Less Good but Not Bad: In Defence of Epicureanism about Death. Pacific Philosophical Quarterly 93: 197-227

Suits, B. (2005). The Grasshopper: Games, Life and Utopia. Broadview Press (Reprint edition)

Warren, J. (2004). Facing Death: Epicurus and his critics. Oxford: OUP.

Worldbank (2016). Fertility rate, total (births per woman) Data - available at: http://data.worldbank.org/indicator/SP.DYN.TFRT.IN

Widerquist, K. (2013). Independence, Propertylessness and Basic Income: A Theory of Freedom as the Power to Say No. New York: Palgrave-Macmillan.

Williams, B. (1973). The Makropulos Case: Reflections on the Tedium of Immortality. In Williams, B. Problems of the Self: Philosophical Papers 1956-1972. Cambridge: Cambridge University Press. 
${ }^{\mathrm{i}}$ In my home university, NUI Galway, there is currently a large EU pilot project taking place on the use of robots for the care of aging patients with dementia. See The MARIO Project - http://www.mario-project.eu/portal/

ii I say 'pragmatic concerns' because the argument for BIG is not a solely pragmatic one. There are several arguments in favour of BIG that derive from philosophical accounts of political freedom. See, for example, Widerquist 2013. iii I was first encouraged to consider this possibility during an interview conducted by Jon Perry and Ted Kupper on the Review the Future Podcast. I would like to thank them both for suggesting this line of inquiry. The podcast itself can be heard at: http://reviewthefuture.com/?p=606 